\title{
TIPOS DE INOVAÇÃO EM MICRO E PEQUENAS EMPRESAS VENCEDORAS DO PRÊMIO NACIONAL DE INOVAÇÃO
}

\section{TYPES OF INNOVATION IN MICRO AND SMALL ENTERPRISES WINNERS OF THE NATIONAL INNOVATION PRIZE}

Recebido em: 31 jul. 2020

Aprovado em: 26 abr. 2021

Versão do autor aceita publicada online: 26 abr. 2021

Publicado online: 30 jun. 2021

Como citar esse artigo - American Psychological Association (APA):

Valois, R. R. L., Paula, S. L., Santana, C. A. Jr., \& Santos, C. F. S. O. (2023, jan./mar.). Tipos de inovação em micro e pequenas empresas vencedoras do prêmio nacional de inovação. Exacta, 21(1), 80-100. https://doi.org/10.5585/exactaep.2021.17814

Submeta seu artigo para este periódico $\beta$

Processo de Avaliação: Double Blind Review

Editor: (D) Dr. Luiz Fernando Rodrigues Pinto

Dados Crossmark 


\title{
TIPOS DE INOVAÇÃO EM MICRO E PEQUENAS EMPRESAS VENCEDORAS DO PRÊMIO NACIONAL DE INOVAÇÃO
}

\author{
TYPES OF INNOVATION IN MICRO AND SMALL ENTERPRISES WINNERS OF THE NATIONAL \\ INNOVATION PRIZE
}

\author{
(iD) Reyza Reis Lira Valois ${ }^{1}$ \\ (i) Silvio Luiz de Paula ${ }^{2}$ \\ (iD Celio Andrade de Santana Junior ${ }^{3}$ \\ iD Claudinete de Fátima Silva Oliveira Santos ${ }^{4}$
}

Resumo: O objetivo geral desse trabalho é analisar os aspectos inovativos das Micro e Pequenas Empresas (MPEs) ganhadoras da edição 2018/2019 do Prêmio Nacional de Inovação (PNI). Como arcabouço teórico, foram utilizados conceitos de empreendedorismo, inovação e políticas públicas de apoio à inovação. O estudo foi de natureza qualitativa, utilizando estudo de múltiplos casos, para tanto, foram pesquisadas as quatro empresas ganhadoras do prêmio na categoria microempresa, realizando-se para a coleta de dados entrevistas semiestruturadas com os sócios das empresas, pesquisa documental e aplicação de questionário. Na análise dos dados utilizou-se a técnica de análise de conteúdo. Dentre os resultados, os sócios apresentaram papel relevante na condução das ações e direcionamento do tipo de inovação adotada, as organizações demonstraram uma cultura forte de inovação. Confirmou-se ainda a importância das políticas públicas de apoio a inovação nas MPEs.

Palavras-chave: Inovação. PNI. MPEs. Políticas Públicas.

Abstract: The general objective of this work is to analyze the innovative aspects of Micro and Small Enterprises winners of the 2018/2019 edition of the National Innovation Award. As theoretical framework, concepts of entrepreneurship, innovation and public policies to support innovation were used. The study was qualitative in nature, using multiple case studies, for this, the four companies that won the award in the microenterprise category were researched, conducting for data collection semi-structured interviews with the partners of the companies, documentary research and application of a questionnaire. For data analysis, the content analysis technique was employed. Among the results, the partners had a relevant role in the conduction of actions and direction of the type of innovation adopted, the organizations showed a strong culture of innovation. It was also confirmed the importance of public policies to support innovation in Micro and Small Enterprises.

Keywords: Innovation. PNI. MSEs. Public Policies.

\footnotetext{
${ }^{1}$ Programa de Pós-Graduação em Propriedade Intelectual e Transferência de Tecnologia para a Inovação (PROFNIT/UFPE) / Mestranda no Programa de Pós-Graduação em Propriedade Intelectual e Transferência de Tecnologia para a Inovação.

2 http://lattes.cnpq.br/3745582117653135 / Depto de Ciência da Informação / Programa de Pós-graduação em Inovação (PROFNIT) / Universidade Federal de Pernambuco / Doutor (2018), mestre (2010) e graduado (2006) em Administração pela Universidade Federal de Pernambuco-UFPE. Professor do Departamento de Ciência da Informação-DCI/UFPE. Professor permanente do Programa de Pós-Graduação em Propriedade Intelectual e Transferência de Tecnologia para a Inovação-PROFINIT/UFPE. Autor de livros, tem experiência na área de administração, com ênfase em Gestão de pessoas, Gestão da informação e Inteligência informacional.

${ }^{3}$ Universidade Federal de Pernambuco / Célio Santana is a professor at Information Science Department on Federal University of Pernambuco. He holds a doctor degree in computer science researching agile software development and Master degree in computer engineering. The recent focus of his research is about business of social media and digital caution on social information.

${ }^{4}$ Universidade Federal de Pernambuco / Doutora (2019) e Mestre em Administração (2010) pela Universidade Federal de Pernambuco, Especialista em Gestão de Pessoas e Negócios pela Faculdade de Filosofia, Ciências e Letras de Caruaru (2006) com Graduação em Administração de Empresas pela Universidade de Pernambuco (2001). Experiência profissional em empreendedorismo, gestão, ensino, instrutoria e consultoria organizacional.
} 


\section{Introdução}

A inovação representa uma oportunidade de melhoria de competitividade para as empresas. Os esforços sobre a inovação em países em desenvolvimento, como o Brasil, necessitam de uma construção de agenda pública que invista em gestão da inovação (Figueiredo, 2013; Kon, 2015). Por essa razão, tornou-se indispensável o estudo sobre inovações nas empresas e o investimento em política públicas, inseridas por meio de programas voltados ao desenvolvimento e implementação da inovação (Coral, Ogliare, \& Abreu, 2011).

A Lei de Inovação ou Lei no 10.973/2004, que propôs incentivos à inovação e à pesquisa científica e tecnológica no ambiente produtivo colaborou para o surgimento de iniciativas como os incentivos da Lei do Bem, por exemplo. Além disso, proporcionou o avanço na reformulação de competências para uma relação mais efetiva entre a academia e a indústria (Brasil, 2004).

Por meio da tipologia de inovação apresentada no Manual de Oslo (OCDE, 2006), a Confederação Nacional da Indústria (CNI) impulsionou a agenda de Políticas Públicas de Inovação no Brasil, construindo um ambiente favorável ao desenvolvimento tecnológico para comtemplar das micro às grandes empresas (CNI, 2005).

Nesse contexto, o Prêmio Nacional de Inovação (PNI) surgiu com o propósito de enaltecer as empresas que desenvolvem esforços inovativos de comunicação e criação de valor, conectando-se com a sociedade, o governo, a concorrência, os fornecedores, entre outros. Desde sua primeira edição no ano de 2008, o prêmio já acumula mais de 11 mil empresas inscritas.

Para Puay et al. (1998), empresas que implementam modelos de prêmios de excelência não somente melhoram a qualidade, mas também melhoram a participação de mercado, satisfação do cliente, lucratividade, processos, desempenho de fornecedores, moral dos empregados e competitividade.

Questiona-se quais são os estímulos gerados pelas políticas públicas de apoio à inovação visando reconhecer os esforços e aumentar a competitividade das MPEs brasileiras? Nesse contexto o presente trabalho foi desenvolvido no sentido de analisar os aspectos inovativos das Micro e Pequenas Empresas (MPEs) ganhadoras da edição 2018/2019 do Prêmio Nacional de Inovação (PNI). Pata tanto, buscou-se compreender a metodologia de avaliação do PNI, criada com base em padrões internacionais de inovação. Realizando posteriormente análises das empresas vencedoras (edição 2018/2019) e das inovações praticadas por elas. 
2 Referencial Teórico

2.1 Inovação

A inovação representa uma oportunidade de melhoria de competitividade para as empresas. Os esforços sobre a inovação em países em desenvolvimento, como o Brasil, necessitam de uma construção de agenda pública que invista em inovação e gestão da inovação nas empresas (Clauss, 2017)

De forma ampla, as inovações podem ser classificadas como radicais ou incrementais. A inovação radical é caracterizada pelo desenvolvimento e a introdução de um novo produto, novo processo ou forma de organização da produção inteiramente nova. Este tipo de inovação pode representar uma disrupção da estrutura anterior, resultando em novas indústrias, setores, mercados, etc (Tidd \& Bessant, 2018). Também apresentam redução de custos e aumento de qualidade dos produtos já existentes. Por outro lado, a inovação incremental é caracterizada pela continuidade ao processo de mudança (Schumpeter, 1934).

Inovações realmente novas são mais raras, representando apenas cerca de 6\% a 10\% de todos os projetos que se dizem inovadores (Tidd \& Bessant, 2015). Esse indicador ressalta que a maior parte das inovações presentes no mercado trata de inovações incrementais.

Todavia, para Coral, Ogliare e Abreu (2011) introduzir no mercado algo novo ou alguma novidade, por si só, não caracteriza uma ação inovadora. Portanto, ser inovador está além de ter boas ideias; é um processo de fazê-las evoluir a ponto de terem um uso prático (Tidd \& Bessant, 2015).

Ainda nesse contexto, é importante distinguir as diferenças entre invenção e inovação. Segundo Tigre (2006) a invenção se refere à criação de um processo, técnica ou produto novo, que pode ser divulgada por meio de artigos técnicos e científicos, registrada em forma de patente, visualizada e simulada por protótipos e plantas piloto sem, contudo, ter uma aplicação comercial efetiva. Portanto, a inovação ocorre com a efetiva aplicação prática de uma invenção.

Segundo Carvalho (2009), a inovação se distingue da invenção pelo fato desta ter vencido todos os obstáculos associados ao seu desenvolvimento e concepção, e ter sido implantado com sucesso no mercado, agregando valor para seus stakeholders.

Schumpeter (1982) adota uma concepção abrangente de inovação, associando-a a tudo que diferencia e cria valor a um negócio. O conceito schumpeteriano de inovação é útil para tratar da gestão tecnológica e organizacional, pois está diretamente focado na melhoria da competitividade de uma empresa no mercado. Por essa razão, tornou-se indispensável o estudo sobre inovação nas empresas e o investimento em política públicas, inseridas através de programas voltados ao desenvolvimento e implementação da inovação (Singh, Khamba, \& Nanda, 2017). 
O conceito de inovação adotado pela Organização para Cooperação e Desenvolvimento Econômico (OCDE), no Manual de Oslo, utiliza a definição de Schumpeter sobre a inovação como sendo a "implantação de um produto novo ou significativamente melhorado, ou um processo, ou novo método de marketing, ou novo método organizacional nas práticas de negócios, na organização do local de trabalho ou nas relações externas" (OCDE, 2005, p.55).

Ainda de acordo com a OCDE (2005), as inovações de produto são entendidas pelas mudanças significativas em um produto ou serviço de uma organização. Nesse tipo de inovação, os produtos referem-se ao desenvolvimento de um bem ou serviço novo ou melhorado, tanto em relação às suas características (componentes, material, funcionalidade ou outros recursos funcionais) quanto ao seu uso planejado, com o objetivo de atender as necessidades dos clientes e impactar positivamente o negócio (Utterback \& Abernathy, 1975).

Nas inovações de processos, as alterações são apresentadas nos métodos de produção e distribuição (OCDE, 2005). Ou seja, trata de modificações nos métodos de produção e entrega por meio de mudanças significativas de técnicas, equipamentos ou softwares, e por meio do redesenho dos principais processos operacionais, visando aumentar a eficiência e produtividade do sistema, reduzindo custo de produção ou melhorando a qualidade de bens e serviços (Scherer \& Carlomagno, 2009).

As inovações de produto e processo podem acontecer de forma independente, porém, ambas podem complementar-se e beneficiar-se entre si. O desenvolvimento de um novo produto pode funcionar como catalisador para a inovação de processo, que por sua vez pode viabilizar a concepção de uma inovação de produto (Zairi, 1995).

A inovação em marketing, está associada à inclusão de mudanças significativas na concepção do produto, ou seja, no design do produto, na embalagem, na promoção e no estabelecimento de preços de bens e serviços, podendo também alterar substancialmente o método de marketing vigente (OCDE, 2005). Nessa inovação também são abordados, por exemplo, as melhorias no atendimento às necessidades do consumidor, bem como a abertura de mercados ou reposicionamento de um produto para o aumento das vendas.

Por último, as inovações organizacionais, segundo a OCDE (2005) referem-se às implementações de novos métodos organizacionais, como na organização do trabalho, ou nas relações externas da empresa, a modificação do conjunto de práticas da organização, assim como sua composição estrutural interna, as relações com terceiros e papel dos colaboradores (Scherer \& Carlomagno, 2009). Esta definição é similar à inovação que Kim, Kumar e Kumar (2012) denominam como inovação administrativa, que visa implantar novas ideias para melhorar o desempenho da estrutura e do sistema administrativo de uma empresa. Esse conceito de inovação está atribuído a, por exemplo, redução de custos administrativos, logística ou suprimentos, aumento da satisfação no local de trabalho e produtividade, entre outros. 
Rogers e Shoemaker (1971, p.56) definem inovação como "uma ideia, uma prática ou um objeto percebido como novo pelo indivíduo". Essa interpretação, por sua abrangência, condiz com o conceito schumpeteriano, pois não associa essencialmente a inovação ao conhecimento científico. Tampouco precisa ser nova para ser inserida no mercado ou no país, não sendo necessário acionar a concorrência. Na prática, muitas inovações são resultados da experimentação vivenciada ou da simples combinação de tecnologias existentes. A fim de identificar as abordagens mais apropriadas para criar planejamentos e projetos de inovação, as empresas têm buscando conhecer mais as tipologias de inovações (Carvalho, 2009). O desenvolvimento econômico é conduzido por um processo dinâmico, em que as novas tecnologias substituem as antigas, um processo de destruição criadora (Khalili, 2017).

Em recente edição, a OCDE (2006) apresenta uma comparação sobre as categorias que fazem parte da tipologia da inovação. Neste contexto, a mais recente edição do guia aborda as inovações atribuídas ao design de produtos em "inovação de produtos", enquanto a edição anterior, incluia na inovação de marketing. Esta mudança ocorreu pelo estreitamento da relação de atividades de design e o desenvolvimento de características de produtos para bens e serviços. No entanto, as mudanças no design das embalagens permanecem inserida na inovação de marketing. No que tange a inovação organizacional, foram acrescidas subcategorias de administração e gestão, antes incluídas na inovação de processo (OCDE, 2006).

Entre os aspectos relacionados à inovação, um componente que é pouco explorado, mas que também pode ser inserido nas atividades de gestão empresarial para aumentar as possibilidades de práticas contínuas, é a ecoinovação (Cheng \& Shiu, 2012). É importante ressaltar que a ecoinovação é um processo contínuo e cíclico, que leva o empreendedor a refletir sobre suas estratégias e o modelo de negócios (Bicen \& Johnson, 2015).

Por fim, ainda sobre a capacidade de inovar, Fontana e Musa (2017) afirmam que a liderança do empreendedor no processo inovativo potencializa a vantagem competitiva, sendo essa um dos motores mais importantes que permitem a competição em escala. Para Çakar e Ertürk (2010), as empresas de médio porte são altamente competitivas no mercado nacional e internacional, reforçando a importância da cultura da inovação e do suporte de políticas públicas que fortaleçam os empreendimentos.

\subsection{Empreendedorismo e Políticas públicas de apoio à inovação no Brasil}

Desde a sua origem, a função do Estado passou por diversas transformações. Entre os séculos XVIII e XIX, seu principal objetivo era a segurança pública e a defesa externa em caso de ataque inimigo. Entretanto, com o aprofundamento e expansão da democracia, as responsabilidades do Estado se diversificaram. Atualmente, afirma-se que a função do Estado é promover o bem estar da sociedade. Para tanto, ele necessita desenvolver uma série de ações e atuar diretamente em diferentes áreas, tais 
como saúde, educação, meio ambiente, entre outros. Para atingir resultados em diversas áreas e promover o bem-estar da sociedade, os governos se utilizam das Políticas Públicas (SEBRAE/MG, 2018)

A política pública, inicialmente conhecida como área de conhecimento e disciplina acadêmica, surgiu nos Estados Unidos da América. Com o objetivo de romper ou pular etapas tradicionais européias de pesquisas e estudos, concentrava-se mais em construir análises sobre o Estado e suas instituições, do que na produção de governos (Souza, 2006).

As políticas públicas são consideradas como o conjunto de programas, ações e atividades desenvolvidas pelo Estado com a participação de entes públicos ou privados, que visam assegurar determinado direito de cidadania; de forma difusa ou para determinado segmento social, cultural, étnico ou econômico (Vaitsman, 2013). A partir disso, surge a necessidade da criação de ambientes cooperativos para envolver esses diferentes segmentos interessados no desenvolvimento tecnológico, e posteriormente, serem realizadas as políticas públicas de ciência e tecnologia com efetividade.

De outra maneira, as políticas públicas são a totalidade de ações, metas e planos que os governos (nacionais, estaduais ou municipais) traçam para alcançar o bem-estar da sociedade e o interesse público.

O modelo da Hélice tríplice (Triple Helix), proposto por Etzkowitz e Leydesdorff (1996), aponta para o papel de cada um dos atores (Governo, Universidade, Indústria) no desenvolvimento tecnológico. Este modelo ressalta a inter-relação dos diferentes atores do desenvolvimento de C\&TI. O Estado, assim como as universidades e empresas, passa a ter a mesma importância no processo, ao contrário do pensamento que o considerava sendo o mais importante desta relação (Etzkowitz \& Leydesdorff, 1996).

O Estado, por muitas vezes visto como percursor de desenvolvimento, encontra entraves a partir de sua incapacidade de gerar avanços de modo efetivo, devido a isso, surge a necessidade de uma maior interação com o setor privado, como as instituições de ensino e as empresas. O principal fator está relacionado com a crise no modelo do estado e com a atuação generalista da administração pública (Mancebo et al., 2006).

Assim, para dar conta de suas demandas, cada vez mais amplas e complexas, o Estado se vê obrigado a buscar recursos por meio de um processo de cooperação, com outros atores sociais, incluindo a iniciativa privada (Schneider, 2005).

Diante disso, Dornelas (2005) ressalta que o empreendedorismo acelerou na década de 1990 e ganhou proporção nos anos 2000, se tornando tema central das políticas públicas na maioria dos países, onde se têm como exemplos: programas de incubação de empresas e parques tecnológicos; desenvolvimento de currículos integrados que estimulam o empreendedorismo em todos os níveis, da educação fundamental à pós-secundária; programas e incentivos governamentais para promover a inovação e transferência de tecnologia; subsídios governamentais para criação e desenvolvimento de novos empreendimentos; criação de agências de suporte ao empreendedorismo e à criação de 
negócios; programas de desburocratização e acesso ao crédito para pequenas empresas; desenvolvimento de instrumentos para fortalecer o reconhecimento da propriedade intelectual, entre outros.

Neste cenário, é evidente a ligação do empreendedorismo ao crescimento econômico, havendo uma conviç̧ão de que o poder econômico dos países depende de seus futuros empresários e da competitividade de seus empreendimentos. Seus resultados positivos são o avanço tecnológico e a geração de novos empregos, além disso, o dinheiro gerado pelos empreendedores geralmente é revertido em novas ações empreendedoras (Britto \& Wever, 2002). O empreendedor é a pessoa que realiza um projeto pessoal, assumindo riscos e responsabilidades, buscando a inovação tanto de bens quanto de serviços em função de uma necessidade existente (Dornelas, 2005).

O espaço das micro e pequenas empresas (MPEs) na economia nacional implica a necessidade de combater as carências do segmento. Estão entre os principais problemas do segmento: dificuldades de acesso ao crédito, à tecnologia e à inovação de processos, falta de capacitação gerencial, baixa capacidade para obter informação e oneração tributária e burocrática para a condução dos negócios no mercado interno e externo (SEBRAE/MG, 2008).

Políticas de empreendedorismo visam fomentar empreendedores (indivíduos) altamente inovadores que possam gerar um alto impacto no crescimento econômico movendo a economia com produtos e serviços com maior valor agregado (Henrekson \& Stenkula, 2009). Algumas ações e programas que foram utilizados - orçamento participativo, renda mínima, parcerias público-privado na provisão de serviços públicos, instituições de microcrédito e fundos de desenvolvimento - podem ser efetivos (Lastres et al., 2003).

Nesse contexto, destaca-se a criação da Lei 10.168/2000, que instituiu o Programa de Estímulo à Interação Universidade-Empresa para o Apoio à Inovação, foi fundida a interação das universidades e centros de pesquisa com o setor produtivo. A lei surgiu em prol do desenvolvimento do país, para que os fundos setoriais de indústria voltados para ciência e tecnologia (C\&T) no Brasil fossem diversificados, e focados no estímulo ao desenvolvimento de pesquisa científica e tecnológica pelo setor produtivo.

Conforme Koeller (2007), em 2003, após a inovação ganhar notoriedade, foi criada a Política Nacional de Ciência, Tecnologia e Inovação, e Política Industrial Tecnológica e de Comércio Exterior (PINTEC). Com o destaque da Lei 10.973/04, conhecida como Lei da Inovação - regulamentada em outubro de 2005 - e a Lei 11.196/05, conhecida como Lei do Bem - regulamentada em novembro de 2005, o apoio voltado à inovação, sob a forma de subvenção e à pesquisa científica e tecnológica, e a econômica voltada para a remuneração de pesquisadores (mestres e doutores) que tenham vínculo empregatício com empresas presentes no Brasil, passaram a apresentar um forte incentivo à interação da pesquisa científica com o setor produtivo. 
Nesse sentido, a Lei Complementar no 123/2006, também conhecida como Lei Geral da Micro e Pequena Empresa, surgiu com o objetivo de instituir um tratamento simplificado, diferenciado e favorecido às MPEs. O propósito insere à promoção de um ambiente favorável para estimular o fortalecimento e a competitividade dos pequenos negócios (BRASIL, 2006).

Além disso, a Lei Geral das MPEs garante tratamento jurídico diferenciado e simplificado nas áreas administrativa, tributária, previdenciária, trabalhista, creditícia e de desenvolvimento empresarial; e também, dispõe sobre a diminuição da carga de impostos e a simplificação dos processos de cálculos e recolhimento, por meio do Simples Nacional (Observatório Da Lei Geral Da Micro E Pequena Empresa, 2015). Importante é que a lei inclui mecanismos de ampliação de oportunidades e fomento, facilitando o acesso as linhas de créditos, oferecidas por instituições financeiras (Tavares, 2007).

\section{Procedimentos Metodológicos}

Esta pesquisa possui abordagem qualitativa, e caracteriza-se ainda como descritiva-explicativa. Quanto as estratégias de pesquisa, é caracterizada como estudo de múltiplos-casos. Nesse contexto, os casos analisados serão os quatro pequenos negócios vencedores do Prêmio Nacional de Inovação da edição de 2018/2019, representados pelas empresas descritas no Quadro 1:

\section{Quadro 1}

Pequenos negócios vencedores do PNI, edição 2018/2019

\begin{tabular}{|l|l|l|l|l|l|}
\hline \multicolumn{1}{|c|}{ Empresa } & UF & \multicolumn{1}{|c|}{ Setor } & \multicolumn{1}{|c|}{$\begin{array}{l}\text { Inovação } \\
\text { Vencedora }\end{array}$} & $\begin{array}{l}\text { Finalistas em } \\
\text { outras } \\
\text { subcategorias }\end{array}$ & $\begin{array}{l}\text { Outros prêmios da } \\
\text { edição 2018/2019 }\end{array}$ \\
\hline $\begin{array}{l}\text { Boulle Móveis de } \\
\text { Fundamento }\end{array}$ & PR & Indústria & $\begin{array}{l}\text { Inovação de } \\
\text { Produto }\end{array}$ & $\begin{array}{l}\text { Inovação em } \\
\text { Processo }\end{array}$ & $\begin{array}{l}\text { Destaque Saúde e } \\
\text { Segurança no } \\
\text { Trabalho (SST) }\end{array}$ \\
\hline $\begin{array}{l}\text { CCLI Consultoria } \\
\text { Linguística }\end{array}$ & SP & Serviço & $\begin{array}{l}\text { Inovação em } \\
\text { Processo }\end{array}$ & $\begin{array}{l}\text { Inovação } \\
\text { Organizacional }\end{array}$ & Não se aplica \\
\hline Editora Belas Letras & RS & Comércio & $\begin{array}{l}\text { Inovação em } \\
\text { Marketing }\end{array}$ & Não se aplica & Não se aplica \\
\hline Topos Informática & BA & Serviço & $\begin{array}{l}\text { Inovação } \\
\text { Organizacional }\end{array}$ & $\begin{array}{l}\text { Inovação em } \\
\text { Processo }\end{array}$ & $\begin{array}{l}\text { Vencedora da } \\
\text { categoria Gestão da } \\
\text { Inovação }\end{array}$ \\
\hline
\end{tabular}

Fonte: elaborado a partir de CNI (2019)

A pesquisa utilizou de variados procedimentos de coleta de dados por meio de três métodos: entrevista individual estruturada, aplicação de questionário e pesquisa documental. 
As entrevistas individuais possibilitaram alcançar uma variedade de impressões e percepções que os diversos grupos possuem em relação as variáveis de estudo. A seguir, apresenta-se o Quadro 2 com o perfil dos entrevistados.

\section{Quadro 2}

Perfil dos empresários vencedores do PNI

\begin{tabular}{|c|c|c|c|c|}
\hline Empresário & Cargo & Gênero & Formação & Tempo de empresa \\
\hline E1 & $\begin{array}{c}\text { Sócio- } \\
\text { proprietário }\end{array}$ & Masculino & Mestrado & 7 anos \\
\hline E2 & $\begin{array}{c}\text { Sócio- } \\
\text { proprietário }\end{array}$ & Masculino & Mestrado & 16 anos \\
\hline E3 & $\begin{array}{c}\text { Sócio- } \\
\text { proprietário }\end{array}$ & Masculino & Mestrado & 18 anos \\
\hline E4 & $\begin{array}{c}\text { Sócio- } \\
\text { proprietário }\end{array}$ & Masculino & Pós-graduação & 26 anos \\
\hline
\end{tabular}

Fonte: Elaboração própria

Os principais documentos da base de análise foram o Regulamento do prêmio, a Revista da premiação, o Questionário de autoavaliação respondido pelas MPEs, o Website das empresas e documentos gerais disponibilizados pelos entrevistados.

Após a divulgação das empresas vencedoras, foi elaborado e enviado um questionário complementar com dez questões. Sobre a análise dos dados, aplicou-se a técnica de análise de conteúdo.

\section{Apresentação dos resultados \\ 4.1 Caracterização das MPEs}

O Prêmio Nacional de Inovação, criado pela Mobilização Empresarial pela Inovação (MEI) e realizado pela Confederação Nacional da indústria (CNI), e pelo Serviço de Apoio às Micro e Pequenas Empresas (SEBRAE), surgiu com a premissa de incentivar e reconhecer os esforços bem-sucedidos de inovação e gestão da inovação nos empreendimentos atuantes no Brasil. De acordo com a CNI (2019), a sexta edição da premiação obteve 1.746 inscrições, com abrangência nacional, garantindo oportunidades as empresas participantes, considerando diferentes portes e níveis de gestão. A cerimônia, realizada no dia 10 de junho de 2019, durante o 8o Congresso Brasileiro de Inovação da Indústria, no Estado de São Paulo, premiou 15 (quinze) Micro, média e grandes empresas brasileiras, dos setores de comércio, indústria e serviços.

Criada em 2000, a empresa familiar do setor moveleiro, Boulle, situada em Curitiba, no estado do Paraná, foi a vencedora da categoria inovação de produto dos pequenos negócios, no Prêmio Nacional de Inovação/CNI 2018/2019. O início da empresa se deu por hobbies do fundador da empresa, 
que fabricava os próprios móveis de sua casa, considerando sua facilidade, criatividade e talento com a madeira. A partir disso, o que era brincadeira tornou-se um negócio rentável.

A empresa paulista CCLI Consultoria Linguística, fundada em 2003, tem como missão principal adequar o processo de aprendizagem para alunos que buscam aprender uma nova língua de forma eficaz. Ao observar que as escolas ofereciam metodologias limitadas de ensino sobre línguas e que não correspondiam aos resultados esperados pelos estudantes, o empresário decidiu criar um modelo, diferente dos existentes, adotando uma nova estratégia associada a consultoria para a área de línguas. Ensinar idiomas de acordo com a necessidade de cada aluno, foi com essa proposta que a CCLI desenvolveu uma metodologia inovadora de consultoria linguística e tornou-se a vencedora da categoria "Inovação em processos" no PNI/CNI, edição 2018/2019.

A empresa Belas Letras, está localizada em Caxias do Sul (RS), é uma editora que está no mercado há 18 anos, e o seu propósito é transformar a interação das pessoas com os livros. A empresa é conhecida pelas obras que tratam de criatividade, viagens, família e gastronomia. E, é composta por uma equipe de autores, revisores, designers, editores, comunicadores, divulgadores, vendedores e leitores. A ação inovadora de marketing premiada, trata-se da campanha "compre 1, doe 1", onde para cada livro vendido, a empresa doa outro, tornando os próprios clientes como agentes de leitura no Brasil. A estratégia que engaja e envolve o comprador na proposta, alavancou as vendas de seu ecommerce, em 2018, impulsionando as vendas da editora, e proporcionou a doação de mais de cinco mil livros.

Sediada no Parque tecnológico da Bahia, a empresa Topos, a única vencedora da região nordeste, oferece soluções e serviços voltados para área de tecnologia da informação. Para o diretor de inovação da empresa, "pensar na gestão da inovação como um conjunto de práticas, sistemas, instrumentos normativos e recursos, sejam eles humano ou tecnológico, permitiu que a Topos pudesse inovar". Há mais de 25 anos, a Topos atua na área de tecnologia da informação e comunicação. A principal inovação organizacional realizada foi a implementação de um novo modelo de negócio, baseada na lógica de aceleração de startups e geração de spin-offs.

A realização do estudo sobre as empresas pesquisadas permitiu perceber a heterogeneidade das micro e pequenas empresas brasileiras, e o universo de possibilidades de soluções criadas para resolver novas questões geradas pela sociedade. Durante a pesquisa, foi observado que cada pequeno negócio funciona de forma singular e se comunica com o mercado de maneira diferente.

Independente do setor, de ser indústria, comércio ou serviços, a presença da inovação é vista nas empresas como sendo geradora de criatividade, novidade e engajamento. Nesse contexto, essas organizações possuem abertura para realizarem práticas inovadoras em seu cotidiano, sendo influenciadas desde o perfil inovador de seus representantes até pela opinião de agentes de inovação externos. Estas particularidades permitiram observar e realizar um comparativo sobre como cada 
empresa buscou utilizar a inovação como uma vantagem competitiva, a ponto de ser reconhecida por esforços contínuos realizados na área que integra a empresa.

\subsection{Contexto de inovação}

A empresa Boulle Móveis, ativa em participações em eventos e feiras internacionais relacionadas à inovação, foi também, finalista na categoria de processo. Apesar de nunca ter participado de prêmios anteriores, a Boulle, incentivada pelo programa Agente Local de Inovação (ALI), oferecido pelo Sebrae em parceria com CNPq, venceu a categoria de "Inovação em Produtos", com a lareira portátil Lug. Sobre o produto vencedor no Prêmio, o empresário destaca que a lareira Lug foi produzida em seis meses, passando por adaptações após a conquista do prêmio, sofrendo alterações em sua fixação, design e acabamento, e que passou de 2,5kg para 3,5kg. Ainda para o empreendedor, o produto é considerado inovador porque se trata de uma peça que toda pessoa pode ter, é inodora, não emite fumaça, seu preço é acessível, além de ter design atrativo, ser portátil e funcional.

O ambiente de inovação da empresa está conectado com a promoção de eventos fechados que recebe profissionais da arquitetura e design, além de abrir suas portas para estudantes que desejam conhecer mais sobre os objetos inovadores do empreendimento. A empresa também ganhou o prêmio na categoria "Destaque em Segurança de Saúde do Trabalho". Apresenta nas inovações de seus produtos autenticidade no design e a busca contínua no aprimoramento de suas criações. Além disso, os avanços em seu processo de fabricação, permite o reaproveitamento de materiais e a construção de novas obras em um menor espaço de tempo. Outro aspecto relevante é a preocupação da empresa com questões de saúde e segurança no trabalho. Para o empresário, que é designer, escutar os colaboradores no processo de criação do produto foi fundamental para a conquista do prêmio pois, eram eles que estavam presentes no processo de fabricação da peça.

Quanto à empresa CCLI, os processos são personalizados para atender o objetivo de cada cliente. Desse modo, a satisfação é o principal condutor das inovações que surgem na empresa. A estrutura foi criada para favorecer o aprendizado dos alunos e encorajá-los a atingir o seu propósito, que é aprender um novo idioma. A vencedora da categoria "Inovação em Processos", a CCLI, implantou em 2017, o serviço de consultoria de idiomas por videoconferência, com metas de monitoramento, o que impulsionou o avanço de aprendizagem dos seus clientes. O planejamento da inovação durou três anos, até a sua finalização, com a criação de indicadores para mesurar os resultados alcançados, e com isso avaliar sua tangibilidade. A empresa também foi finalista na categoria "Inovação Organizacional". Com isso, percebeu que inovação se deu pelo monitoramento dos resultados, e os seus impactos.

A Belas Letras proporciona um ambiente criativo de aprendizado aliando às estratégias para uma maior aproximação com público e interação com parceiros. Suas inovações em marketing são estrategicamente inseridas no mercado agregando valor social e na interação com os clientes. Inserida 
em um contexto inovador, a editora Belas Letras, criou a estratégia de marketing "Compre 1 e Doe 1", em que para cada livro comprado, outro é doado. A empresa levou em média dois anos para realizar mudanças em seu modelo de vendas e inserir no mercado a ação inovadora, que conquistou a categoria “Inovação em Marketing" na sexta edição do PNI (2018/2019). A empresa possui ativos intelectuais como o registro da marca Belas Letras no Instituto Nacional da Propriedade Industrial (INPI) e mais de 100 licenças de uso de direitos autorais estrangeiros para comercialização no Brasil. Além disso, o que considera ter sido relevante para a conquista do prêmio foi a cultura da empresa e os resultados expressivos, obtidos por suas inovações.

A empresa Topos Informática oferece suas soluções e serviços no segmento de Tecnologia da Informática e Comunicação (TIC), proporcionando ao seu público facilidade quanto às necessidades ligadas desde consultoria à geoprocessamento. A empresa também desenvolve produtos e investe em soluções construídas por startups. Por ter como um de seus valores a inovação, a Topos Informática estabelece em seu planejamento estratégico objetivos e ações voltadas para a temática. Para fomentar novos projetos com potencial de sucesso, a empresa conta com recursos internos (humanos, infraestrutura, equipamentos etc.), além da contratação de consultoria para capacitar na temática de Gestão da Inovação. A cultura de inovação da Topos é percebida não só em termos de práticas e processos estruturados, como também no próprio layout e ambiente organizacional da empresa.

A organização está sediada em um Parque Tecnológico e adota o conceito open office: ambiente com o workplace sem barreiras entre as áreas funcionais e as equipes produtivas. A Topos possui práticas que potencializam a integração dos colaboradores, clientes e fornecedores, a exemplo de ações denominadas BytePapos. A participação no PNI esteve relacionada a uma estratégia de posicionamento da empresa no mercado em que atua. Com sua cultura organizacional e estratégias inovadoras, o empreendimento projeta desde o planejamento à captação de seus recursos. Eleita como a vencedora nas categorias "Gestão da Inovação" e "Inovação Organizacional", a Topos se destacou por implantar um novo modelo de negócio, baseado na lógica de aceleração de startups e geração de spin-offs. A empresa também foi finalista na categoria "Inovação em Processos".

\section{Discussão dos resultados}

Ao considerar a metodologia criada para o Prêmio Nacional de Inovação, elaborada pelo CNI e SEBRAE em 2018, as empresas vencedoras corresponderam às dimensões de inovação, baseadas nos conceitos de Gestão da Inovação, que por sua vez é entendida como o resultado da interação sinérgica entre os Fundamentos da Capacidade de Inovação e os Resultados da Inovação, que estão associados as dez dimensões a seguir: 
I. Aprendizagem organizacional: Como o conhecimento e as ideias figuram entre algumas das entradas primárias no processo de inovação, as organizações podem usar a aprendizagem para reduzir incertezas e ambiguidades inerentes à inovação. Assim, está fundamentada na aprendizagem sobre erros cometidos no passado, posturas, preferências e comportamento dos clientes, bem como no aprendizado sobre produtos e estratégias dos concorrentes (LAWSON; SAMSON, 2001).

II. Cultura de inovação: Traz a cultura e o clima organizacional como fatores determinantes no processo de inovação. Entre os componentes subjacentes à cultura e ao clima, pode-se citar a tolerância à ambiguidade, o empowerment, a disposição para correr riscos calculados, entre outros. Nesse aspecto, é fundamental respeitar e investir nas pessoas. Além disso, está intimamente associada ao conceito de estruturas organizacionais descentralizadas e com muito envolvimento e comprometimento das pessoas (PRAJOGO; AHMED, 2006).

III. Estratégia orientada à inovação: Este fundamento aborda quais as estratégias são determinantes para a configuração dos recursos, produtos, processos e sistemas que as empresas adotam para lidar com incertezas existentes em seu ambiente. No entanto, a inovação não é simplesmente uma consequência da estratégia, podendo também influenciá-la de forma que as escolhas estratégicas sejam redefinidas pela inovação (FRANCIS, 2000; OTTAVIANO, 2004).

IV. Estrutura favorável à inovação: Caracteriza-se pelo arcabouço presente nas empresas inovadoras que estimulam a criação de fronteiras permeáveis nos seus negócios, ajudando a quebrar barreiras entre funções, departamentos e grupos. Quanto mais permeável e orgânica a estrutura, maior será o potencial para que ideias inovadoras surjam (LAWSON; SAMSON, 2001).

V. Recursos financeiros disponíveis para a inovação: Trata da disponibilidade e correta alocação de recursos, fatores determinantes para os resultados competitivos das empresas. Assim, um projeto adequado de orçamento, com destinações específicas, é fundamental para uma iniciativa de inovação bem-sucedida (PERDOMO-ORTIZ et al., 2006).

VI. Liderança comprometida com a inovação: Trata da presença e do compromisso do líder no desenvolvimento e sucesso das ações de inovação. A liderança é fundamental, principalmente na implementação de inovações radicais, quando é exigido um nível de aprendizagem e mudança muitas vezes arriscado e caro. O comprometimento requer energia, recursos e poder - primariamente detidos e controlados pelos líderes - que devem ser utilizados para vencer a inércia organizacional (PRAJOGO; e AHMED, 2006).

VII. Marketing para a inovação: O mercado é o árbitro do sucesso de uma inovação, não a empresa que a desenvolve. A voz do cliente é transformada em iniciativas de inovação, as quais podem ser desenvolvidas ou abandonadas, uma vez que as pessoas podem mudar seus critérios de compra com grande rapidez. Além disso, as iniciativas dos concorrentes são frequentemente surpreendentes e 
podem ocupar algum ou todo o espaço disponível de uma oportunidade de mercado (FRANCIS, 2000).

VIII. Pessoas orientadas à inovação: Subjacente aos princípios relacionados à inovação, as pessoas e práticas sociais constituem elementos básicos para o sucesso das iniciativas inovadoras. Portanto, esforços devem ser dirigidos para a gestão de pessoas, e devem ser prioritariamente focados na criação e manutenção de um ambiente favorável à inovação, de modo que as pessoas não se sintam apenas motivadas a inovar, mas tenham reais oportunidades e meios para isso (PRAJOGO; AHMED, 2006).

IX. Processos habilitadores da inovação: No contexto das ações inovadoras, os processos podem gerar vantagens competitivas transformadas em melhorias organizacionais que proporcionam a diferenciação da empresa no mercado. Assim, os processos estão diretamente relacionados à melhoria da eficácia e da eficiência da produção (ESSMANN, 2009).

X. Relacionamentos com o ambiente externo: Ainda que as organizações possam inovar por conta própria, o processo é facilitado pela existência de um conjunto de relações e pela troca de conhecimentos entre pares. As relações com outras instituições também podem facilitar o fluxo de informações e conhecimentos, mediante a criação e intensificação de redes de contato e cooperação (RAMMER et al., 2009).

As dez premissas foram observadas nas empresas premiadas a partir das características trazidas inicialmente como forma de conhecimento e posteriormente transformadas em esforços inovadores. Percebeu-se que a partir das demandas do mercado, novas características relacionadas à inovação foram sendo incorporadas pelas empresas. A inovação, antes vista como diferencial competitivo, passa a ter conotação fundamental no que diz respeito aos processos internos e externos das empresas.

Para a empresa Topos, por exemplo, a criação de tópicos correspondentes à sua forma de se relacionar com a inovação possibilitou a realização de planejamento de ações inovadoras, com diretrizes em uma perspectiva factível. Nesse caso, a empresa definiu diversas metas estratégicas, que resultaram na criação de um setor específico para o desenvolvimento do processo de gestão da inovação.

Compreende-se que a inovação é tratada de forma diferente em cada empresa analisada. Mesmo que não haja um entendimento sobre a tipologia da inovação e que as organizações não inovem de maneira proposital, elas obtêm resultados quando aplicam em seus produtos e serviços novas possibilidades a partir dos recursos que já possuem, sem ter que realizar investimentos altos ou outros esforços. É visto que a inovação também acontece de forma orgânica, com desprendimento de crenças e criação de ambientes favoráveis a novas ideias. Na Editora Belas Letras, o ambiente de trabalho e a cultura da empresa fazem com que a inovação seja, de alguma forma, nativa em quem entra para a equipe. 
Para o empresário da CCLI, por exemplo, a inovação de maior impacto foi implantada quando ele percebeu que a solução estava na ruptura com a metodologia padrão utilizada nas escolas e decidiu adotar princípios mais estratégicos, encontrados na metodologia de trabalho de uma consultoria para a área de línguas.

As características observadas com maior frequência nas empresas estudadas tratam das inovações oriundas de estímulos sobre os ativos intelectuais que geram ideias, que posteriormente são transformadas em inovações. Os novos negócios criados no âmbito organizacional nascem de acordo com experiências extraídas do cotidiano, por parte de colaboradores, e das parcerias realizadas com atores e empresas pertencentes a outros tipos de negócios.

Rodrigues e Veloso (2013) afirmam que a criatividade é uma condição fundamental para que a inovação ocorra com sucesso, exigindo a existência de um clima organizacional favorável ao seu desenvolvimento.

O campo da inovação em rede envolve diferentes atores, tais como universidades, empresas, agências de fomento e governo. Essas redes têm emergido como uma nova forma de organização para a produção do conhecimento, permitindo a redução de riscos e do grau de incerteza, especialmente em campos mais novos da ciência (PELLEGRIN et al., 2007). Nesse contexto, foi percebida também a adesão de todas as empresas estudadas ao Programa ALI, que promove a prática continuada das ações de inovação em empresas de pequeno porte, por meio de orientação proativa, gratuita e personalizada (SEBRAE, 2020).

\section{Conclusão}

O objetivo desta pesquisa foi apresentar os tipos de inovação das Micro e Pequenas Empresas a fim de analisar os esforços geradores de premiação no Prêmio Nacional de Inovação da edição 2018/2019. Para tanto, foram questionados quais são os estímulos gerados pelas políticas públicas de apoio à inovação para reconhecer os esforços e aumentar a competitividade das MPEs brasileiras.

Os resultados denotam que os esforços geradores de inovação nas empresas se referem a ações praticadas anteriormente ao prêmio, e que os efeitos estabelecem transformações no desempenho por meio de motivações que independem das políticas públicas vigentes.

O estudo realizado demonstra que, apesar dos desafios e do baixo estímulo oferecido, das dificuldades de financiamentos com a finalidade de inovar, entre outros, os estímulos para a inovação são gerados pelas MPEs, no que tange o trabalho em equipe, a busca por conhecimento e pela sobrevivência das empresas nas áreas atuantes. Embora de forma ainda tímida, as políticas públicas contribuem com o apoio à inovação reconhecendo os esforços particulares das organizações por meio de premiações como o Prêmio Nacional de Inovação, incentivando o aumento da competitividade das MPEs brasileiras. 
Os resultados indicam que as MPEs apresentam capacidade de realizar atividades relacionadas à inovação, incluindo práticas que não se restringem somente aos grandes negócios. As empresas determinam o direcionamento de recursos, sejam financeiros ou na forma de capital intelectual, para o desenvolvimento estratégico da inovação.

Visando estimular as empresas e promover maior engajamento inovativo nos pequenos negócios, de forma contínua e sustentável, através dos casos de sucesso atribuídos ao Prêmio, buscouse descrever as características das empresas premiadas da edição 2018/2019. Apresentou-se o desempenho geral das empresas em relação ao posterior recebimento do prêmio, sendo considerados os destaques sobre os tipos de inovação realizados nos últimos dois anos. Para este estudo, delimitouse a análise das categorias Gestão da Inovação e Inovação, bem como suas subcategorias produtos, processo, marketing e organizacional.

Os resultados também expuseram o contexto de inovação das empresas ganhadoras do Prêmio, as quais participaram e investiram em serviços relacionados ao conhecimento sobre inovação e estudos sobre a temática, não se limitando em criar estratégias baseadas em suas experiências, mas também agindo estrategicamente do ponto de vista mercadológico, buscando personalizar seus serviços e vendas.

Por fim, foram analisadas as dimensões de inovação determinadas pelo Prêmio, as quais contribuíram para o entendimento dos aspectos abordados pela metodologia proposta e das características presentes nas empresas vencedoras, considerando a Capacidade de Inovação e os Resultados da Inovação presentes nas MPEs.

Os dados apontaram para algumas semelhanças entre os empreendimentos pesquisados, dos setores de indústria, comércio e serviços, e que foram vencedores da última edição do PNI. Em primeiro lugar, interessante documentar todo o histórico da premiação, desde sua concepção, e torná-lo público, para dar maior credibilidade ao prêmio. A segunda observação se deve à premiação em si: embora as recompensas atuais sejam estimulantes, uma premiação em valores tornaria a competição mais disputada. A participação das empresas no Prêmio, as reflexões trazidas por sua metodologia e os impactos significativos causados nas MPEs vencedoras após sua participação poderiam ser medidos através de uma comunicação com empresários, de modo que relatassem suas experiências pessoais em relação ao prêmio.

Em contraponto, o prêmio possibilita a reflexão dos empresários sobre questões antes não observadas, que têm o potencial de trazerem ganhos antes inexplorados. As futuras MPEs participantes podem estudar as empresas vencedoras do prêmio, com a finalidade de tomar como exemplo as ações postas em prática que levaram a conquista do prêmio. Desse modo, é possível antever as atividades de inovação consideradas efetivas, mesmo para empresas que não pretendem participar da premiação. É 
importante considerar que a competitividade entre as empresas resultou em novos produtos e serviços oferecidos à sociedade.

Além disso, comparado a outros modelos de inovação, o Prêmio Nacional de Inovação deveria inserir em sua avaliação a gestão como requisito preliminar para participação em edições posteriores. Nesse contexto, pode-se afirmar que o desejável é que as empresas estejam alinhadas no que se refere à gestão, para que posteriormente possam inovar com maior efetividade.

As premiações contribuem através do reconhecimento de esforços gerados pelas empresas. As recompensas, que variam de valores financeiros a viagens de imersão em ecossistema de inovação, cooperam para a continuidade da inovação nas MPEs. Com isso, o PNI pode ser considerado um parâmetro que mensura o grau de inovação das empresas brasileiras.

Como limitações deste estudo, destaca-se o fato de não existirem dados precisos sobre o histórico do Prêmio Nacional de Inovação em seus materiais disponíveis. Embora os resultados obtidos neste estudo confiram uma orientação teórica e sirvam como subsídio para as ações e estratégias nas empresas.

Sugere-se para estudos futuros a criação de instrumento de gestão a partir dos indicadores do prêmio, assim como um estudo sobre as mudanças (positivas e negativas) nas empresas vencedoras após conquista do prêmio e, por fim, como estimular a participação de empresários em prêmios de inovação. Também nessa linha, um campo promissor de pesquisa é a investigação, de modo mais aprofundado, do relacionamento de cada dimensão do prêmio com os quatro tipos de inovação abordados pelo Manual de Oslo.

\section{Referências}

Bicen, P., \& Johnson, W. H. A. (2015). Radical innovation with limited resources in high-turbulent markets: the role of lean innovation capability. Creativity and Innovation Management, 24(2), 278-299.

Brasil. Lei Complementar № 123, DE 14 DE DEZEMBRO DE 2006. O Estatuto Nacional da Microempresa e da Empresa de Pequeno Porte. Brasília, DF, 2006. Disponível em: http://www.planalto.gov.br/ccivil_03/leis/lcp/lcp123.htm. Acesso em: 10 mai. 2020.

BRASIL. Lei no 10.973/2004. Dispõe sobre incentivos à inovação e à pesquisa científica e tecnológica no ambiente produtivo e dá outras providências. Brasília (DF): Congresso Nacional; 2004.

Britto, F., \& Wever, L. (2002). Empreendedores Brasileiros. São Paulo: Negócio Editora. 
Çakar, N. D., \& Ertürk, A. (2010). Comparing innovation capability of small and medium-sized enterprises: examining the effects of organizational culture and empowerment. Journal of Small Business Management, 48(3), 325-359. doi: 10.1111/j.1540-627X.2010.00297

Carvalho, M. M. (2009). Inovação: Estratégias e Comunidades de Conhecimento. São Paulo: Atlas.

Cheng, C. C., \& Shiu, E. C. (2012). Validation of a proposed instrument for measuring eco-innovation: an implementation perspective. Technovation, 32(6), 329-344.

Clauss, T. (2017). Measuring business model innovation: conceptualization, scale development, and proof of performance. R\&D Management, 47(3), 385-403.

Confederação Nacional da Indústria (CNI) (2005). Políticas públicas de inovação no Brasil: a agenda da indústria. Confederação Nacional da Indústria. Brasília.

Coral, E., Ogliare, A., \& Abreu, A. F. (Org.) (2011). Gestão Integrada da Inovação: estratégia, orgañização e desenvolvimento de produtos. São Paulo: Atlas.

Dornelas, J. C. A. (2005). Empreendedorismo: Transformando ideias em negócios. 2. ed. Rio de Janeiro: Elsevier.

Essmann, H. E. (2009). Toward Innovation Capability Maturity. Tese de Doutorado - Stellenbosch, South Africa: Stellenbosch University.

Etzkowitz, H., \& Leydesdorff, L. (1996). A triple helix of academic-industry government relations: Development models beyond 'capitalism versus socialism'. Current Science, 70 (8), p. 690-693.

Figueiredo, P. N. (2013). Gestão da inovação: conceitos, métricas e experiências de empresas no Brasil. Rio de Janeiro: LTC.

Fontana, A., \& Musa, S. (2017). The impact of entrepreneurial leadership on innovation management and its measurement validation. International Journal of Innovation Science, 9(1), 2-19.

Francis, D. L. (2000). Assessing and Improving Innovation Capability in Organisations. Tese de Doutorado-Brighton, UK: University of Brighton.

Henrekson, M., \& Stenkula, M. (2009). Entrepreneurship and public policy, IFN Working Paper no 804. 
Khalili, A. (2017). Creative and innovative leadership: measurement development and validation. Management Research Review, 40(10), 1117-1138.

Kim, D., Kumar, V., \& Kumar, U. (2012). Relationship between quality management practices and innovation. Journal of Operations Management, 30 (2), p. 295-315.

Koeller, P. (2007). O papel do estado e a política de inovação. Rede Sist., Universidade Federal do Rio de Janeiro.

Kon, A. (2015). Nova economia política dos serviços. São Paulo: CNPQ.

Lawson, B.; Samson, D. (2001). Developing innovation capability in organisations: a dynamic capabilities approach. International Journal of Innovation Management, 5(3), p. 377-400.

Lastres, H. M. M., Arroio, A., \& Lemos, C. (2003). Políticas de apoio a pequenas empresas: do leito de Procusto à promoção de sistemas produtivos locais. In: LASTRES, Helena Maria Martins; CASSIOLATO, José Eduardo; MACIEL, Maria Lucia Pequena Empresa: cooperação e desenvolvimento local. Rio de Janeiro: Relume Damará.

Mancebo, D., Maués, O. \& Chaves, V. L. J. (2006). Crise e reforma do Estado e da Universidade Brasileira: implicações para o trabalho docente. Crisis and reform of Brazilian State and University: implications. Educar em Revista, 3(28), p. 37-53.

Observatório Da Lei Geral Da Micro E Pequena Empresa (2020). Histórico da Lei Geral. Brasília, 2015. Disponível em: http://www.leigeral.com.br/. Acesso em: 05 maio 2020.

Organização para Cooperação Econômica e Desenvolvimento (OCDE). Manual de Oslo: diretrizes para coleta e interpretação de dados sobre inovação. 3. ed. Brasília: FINEP, 2006.

Organisation for Economic Co-Operation and Development (OECD). Manual de Oslo: diretrizes para coleta e interpretação de dados sobre inovação. FINEP, 2005.

Ottaviano, M. E. (2004). Assessing and improving the enablers of innovation: the development of an Innovation Capability Assessment instrument. Tese de Doutorado - Austrália: Australian Graduate School of Entrepreneurship at Swinburne University of Technology. 
Pellegrin, I.; Balestro, M.; Antunes Júnior, J. A. V.; Caulliraux, H. M. (20202). Redes de inovação: construção e gestão da cooperação pró-inovação. RAUSP Management Journal, 42(3), p. 313325.

Perdomo-Ortiz, J.; González-Benito, J.; Galende, J. (2006). Total quality management as a forerunner of business innovation capability. Technovation, 26(10), p. 1170-1185.

Prajogo, D. I.; Ahmed, P. K. (2006). Relationships between innovation stimulus, innovation capacity, and innovation performance. $R$ and D Management, 36(5), p. 499-516.

Puay, S. H.; Tan, K. C.; Xie, M.; Goh, T. N. (1998). A comparative study of nine national quality awards. The TQM Magazine, West Yorkshire, 10 (1), p. 30-39, 1998.

Rammer, C.; Czarnitzki, D.; Spielkamp, A. (2009). Innovation success of non-R\&Dperformers: substituting technology by management in SMEs. Small Business Economics, 33(1), p. 35-58.

Rodrigues, Ana Filipa; Veloso, Ana. (2013). Contribuições da gestão de recursos humanos para a criatividade e inovação organizacional. Revista Psicologia Organizações e Trabalho, Florianópolis, 13(3), p. 293-308, 2013.

Rogers, E., \& Schoemaker, F. (1971). Communication of Innovations: A Cross Cultural Approach. Free Press.

Singh, D., Khamba, J. S., \& Nanda, T. (2017). Influence of technological innovation on performance of small manufacturing companies. International Journal of Productivity and Performance Management, 66(7), 838-856.

Scherer, F. O., \& Carlomagno, M. S. (2009). Gestão da Inovação na prática: como aplicar conceitos e ferramentas para alavancar a Inovação. São Paulo: Atlas.

Schumpeter, J. A. (1982). Teoria do desenvolvimento econômico: uma investigação sobre lucros, capital, crédito, juro e o ciclo econômico. São Paulo: Abril Cultural.

Schumpeter, J. A., \& Nichol, A. J. (1934). Robinson's Economics of Imperfect Competition. Journal of Political Economy 42(2), p.249-259. 
Schneider, V. (2005). Redes de políticas públicas e a condução de sociedades complexas. Civitas Revista de Ciências Sociais, 5(1), p. 29-57.

Serviço Brasileiro de Apoio às Micro e Pequenas Empresas (SEBRAE). Políticas Públicas: conceitos e práticas. Série Políticas Públicas. Belo Horizonte: Sebrae/MG, v. 7, 2008. Disponível em: http://www.bibliotecas.sebrae.com.br/chronus/ARQUIVOS_CHRONUS/bds/bds.nsf/E0008AOF 54CD3D43832575A80057019E/\$File/NT00040D52.pdf Acesso em: 06 jun. 2020.

Souza, C. (2006). Políticas públicas: uma revisão da literatura. Sociologias, 8(16), p. 20-45, Porto Alegre.

Tavares, D. (2007). Lei Geral das Micro e Pequenas Empresas já está em vigor - Lei Geral: Começa um novo ciclo de desenvolvimento para os pequenos negócios. Revista SEBRAE, 2(20), p. 20-39.

Tidd, J., Bessant, J. (2015). Gestão da inovação. Porto Alegre: Bookman.

Tidd, J., \& Bessant, J. (2018). Innovation management challenges: from fads to fundamentals. International Journal of Innovation Management, 22(5), 1840007

Tigre, P. B. (2006). Gestão da Inovação: a economia da tecnologia no Brasil. Rio de Janeiro: Elsevier. Utterback, J. M., \& Abernathy, W. J. (1975). A Dynamic Model of Process and Product Innovation. OMEGA, 3(6), p. 639-656.

Vaitsman, J., Ribeiro, J. M., Lobato, L. (2013). Policy analysis in Brazil. Bristol: University of Bristol. Zairi, M. (1995). Moving from continuous to discontinuous innovation in FMCG: a re-engineering perspective. World Class Design to Manufacture, 2(5), p. 32-37. 